\title{
Detection of Japanese PRTR Chemicals in a River Affected by Effluent from Industrial and Sewage Facilities
}

\author{
Saori MIHO, Takashi KAMEYA, Takeshi KOBAYASHI, Koichi FUJIE \\ Faculty of Environment and Information Sciences, Yokohama National University, 79-7 \\ Tokiwadai, Hodogaya, Yokohama 240-8501, Japan
}

\begin{abstract}
There has been little long-term environmental monitoring for specified chemicals and information on PRTR chemicals in the water environment is necessary in order to evaluate and manage environmental risks. In this study, river water was collected at eight sites of an urban river in each season from 2010 to 2013, and environmental monitoring was performed on 359 PRTR chemicals (388 including isomers) using GC/MS and LC/MS/MS. As a result, 232 PRTR chemicals were detected. Most of the chemicals detected were for industrial use, with very low concentrations (less than $0.1 \mu \mathrm{g} / \mathrm{L}$ ), and low detection ratios. This is the first large-scale monitoring of PRTR chemicals in Japan, and the need for and usefulness of environmental monitoring of PRTR chemicals have been confirmed.
\end{abstract}

Keywords: chemicals management, environmental monitoring, PRTR, river water

\section{INTRODUCTION}

A wide variety of chemicals are used in industry and society. The World Summit on Sustainable Development (WSSD) in 2002 adopted an international agreement to minimize the impact of chemicals on human health and the environment by 2020 . Toward this goal, the Strategic Approach to International Chemicals Management (SAICM) was defined to develop better methods and criteria for determining the impact of chemicals on human health (UNEP, 2006). It is also emphasized in SAICM that reliable, affordable and practical analytical techniques for monitoring of chemicals for which there is significant concern in environmental media and biological samples should be developed and shared to assess the levels of contaminants in the environment.

In Japan, the Act on Confirmation, etc. of Release Amounts of Specific Chemical Substances in the Environment and Promotion of Improvements to the Management Thereof was established in 1999 (MOE, 2003). In this act, the pollutant release and transfer register (PRTR) scheme and the material safety data sheet (MSDS) scheme were defined, and the voluntary management for use of chemicals in each office was required. In the Japanese PRTR act, 562 chemicals for livelihood, industry or farming have been specified from the viewpoints of their hazard and environmental release. However, the status of use and environmental behavior of the PRTR chemicals are not well known, and therefore establishing their appropriate management is an urgent issue. Specifically, the concentrations of many PRTR chemicals in the environment have to be monitored in order to appropriately evaluate their environmental risks and to conduct reasonable management.

Address correspondence to Takashi Kameya, Faculty of Environment and Information Sciences, Yokohama National University, Email: kameya@ynu.ac.jp

Received May 23, 2014, Accepted September 9, 2014. 
In this study, simultaneous environmental monitoring of 359 PRTR chemicals (388 including isomers) was conducted, and the detection results were analyzed statistically. Firstly, the number of detected or non-detected chemicals was compared with the data obtained from the PRTR report. Secondly, the characteristics of the water quality were identified by checking the uses of the chemicals detected. Thirdly, the detection frequencies and concentration levels were compared at each monitoring targets. Fourthly, the difference in the chemicals detected at each site and each season were investigated. Based on these results, the usefulness and necessity of environmental monitoring for PRTR chemicals were confirmed.

\section{MATERIALS AND METHODS Monitoring target PRTR chemicals}

The list of target chemicals for environmental monitoring, all of which are specified as Japanese PRTR chemicals, is shown in Table 1 using their PRTR registration numbers. For each sample, 388 chemicals were analyzed in total, but there are only 359 chemicals on the list because some chemicals have isomers. For the names and properties of each chemical, please check the Chemical Risk Information Platform (CHRIP) (NITE, 2008).

Table 1 - List of target chemicals specified in the Japanese PRTR Act.

$1-2,1-5,1-6,1-7,1-15,1-16,1-17,1-18,1-19,1-21,1-22,1-23,1-24,1-25,1-26,1-27,1-29,1-32,1-34$, $1-37,1-38,1-39,1-40,1-41,1-42,1-46,1-47,1-48,1-49,1-50,1-51,1-52,1-53,1-54,1-64,1-67,1-69$, $1-73,1-74,1-76,1-78,1-79,1-80,1-81,1-83,1-86,1-89,1-90,1-91,1-92,1-93,1-95,1-96,1-97,1-100$, 1-101, 1-102, 1-109, 1-110, 1-111, 1-112, 1-113, 1-114, 1-115, 1-116, 1-117, 1-118, 1-119, 1-120, 1-121, $1-124,1-125,1-129,1-130,1-133,1-135,1-138,1-140,1-141,1-143,1-145,1-146,1-147,1-148,1-153$, $1-154,1-155,1-156,1-160,1-162,1-165,1-166,1-167,1-168,1-169,1-170,1-171,1-172,1-173,1-174$, $1-175,1-180,1-181,1-182,1-183,1-184,1-188,1-189,1-190,1-191,1-192,1-193,1-194,1-195,1-196$, 1-197, 1-198, 1-200, 1-201, 1-202, 1-203, 1-204, 1-205, 1-206, 1-207, 1-208, 1-212, 1-213, 1-214, 1-215, $1-216,1-217,1-221,1-222,1-223,1-224,1-225,1-229,1-230,1-231,1-233,1-236,1-240,1-245,1-246$, $1-247,1-248,1-249,1-250,1-251,1-252,1-253,1-254,1-258,1-259,1-260,1-261,1-262,1-265,1-266$, 1-269, 1-271, 1-273, 1-275, 1-277, 1-281, 1-283, 1-286, 1-287, 1-289, 1-290, 1-291, 1-292, 1-293, 1-294, $1-295,1-296,1-297,1-299,1-301,1-302,1-306,1-311,1-312,1-314,1-315,1-316,1-319,1-320,1-323$, $1-324,1-326,1-328,1-330,1-331,1-334,1-335,1-336,1-338,1-339,1-340,1-344,1-345,1-346,1-347$, $1-348,1-349,1-350,1-352,1-353,1-354,1-355,1-356,1-357,1-358,1-359,1-361,1-362,1-363,1-364$, $1-365,1-367,1-368,1-369,1-370,1-371,1-373,1-376,1-383,1-388,1-389,1-390,1-391,1-393,1-397$, 1-398, 1-402, 1-403, 1-404, 1-408, 1-409, 1-410, 1-413, 1-414, 1-416, 1-417, 1-418, 1-419, 1-422, 1-425, $1-426,1-427,1-428,1-429,1-430,1-431,1-432,1-434,1-435,1-436,1-438,1-439,1-440,1-441,1-442$, $1-443,1-444,1-445,1-446,1-447,1-449,1-450,1-451,1-452,1-454,1-457,1-458,1-459,1-460,1-461$, $1-462,2-2,2-3,2-5,2-6,2-8,2-9,2-10,2-11,2-13,2-15,2-18,2-19,2-20,2-21,2-22,2-23,2-26,2-28$, 2-29, 2-30, 2-31, 2-32, 2-33, 2-34, 2-35, 2-36, 2-37, 2-41, 2-42, 2-43, 2-44, 2-45, 2-46, 2-47, 2-48, 2-49, 2-50, 2-51, 2-52, 2-53, 2-55, 2-56, 2-57, 2-58, 2-59, 2-60, 2-62, 2-63, 2-64, 2-66, 2-67, 2-68, 2-69, 2-70, 2-71, 2-72, 2-74, 2-75, 2-76, 2-77, 2-78, 2-79, 2-80, 2-81, 2-82, 2-83, 2-86, 2-88, 2-89, 2-90, 2-91, 2-92, 2-94, 2-95, 2-96, 2-97, 2-98, 2-99

* There are only 359 chemicals on this list because some chemicals have isomers, although the monitoring targets in this study are 388 chemicals. 


\section{Sample collection and pretreatment}

River water sampling was conducted at an urban river, Sakai River, in Japan's Kanagawa Prefecture, in each season from 2010 to 2013. The locations of the river water monitoring sites are shown in Fig. 1. In total, 96 environmental water samples were collected from eight of the public water quality monitoring sites officially specified by the local government of Kanagawa Prefecture.

Sakai River basin has factories and residential areas alternately from upstream to downstream, and also four sewage treatment plants (STPs) within a relatively short flow of about $40 \mathrm{~km}$. The effluents from two STPs (A and B) are discharged into Sakai River between Site 2 and Site 3, and the effluents from the other two STPs are discharged into Sakai River between Site 5 and Site 6. Site 6 (2) is a site on one of Sakai River's tributaries.

The diagram of the pretreatment procedure used in this study is shown in Fig. 2. Water samples were concentrated using a solid-phase extraction (SPE) method using the Sep-Pak ${ }^{\circledR}$ Plus PS-2 (Nihon Waters K. K., Tokyo, Japan) cartridge and the Sep-Pak ${ }^{\circledR}$ Plus AC-2 (Nihon Waters K. K., Tokyo, Japan) cartridge. At the beginning of the SPE method, pre-conditioning was performed for each cartridge. The collected water samples were filtrated using a $1-\mu \mathrm{m}$ glass fiber filter, then $25 \mathrm{~g} / \mathrm{L}$ of sodium chloride and $4 \mathrm{~mL} / \mathrm{L}$ of $0.5 \mathrm{M}-\mathrm{H}_{3} \mathrm{PO}_{4}$ buffer were added. A total of $1 \mathrm{~L}$ of the sample solution was supplied to the series of PS-2 and AC-2 cartridges at a flow rate of $15 \mathrm{~mL} / \mathrm{min} \times 67$ min. Three hundred and fifty $\mathrm{L}$ of $\mathrm{N}_{2}$ was used for drying the cartridges $(1 \mathrm{~L} / \mathrm{min} \times 35$ $\mathrm{min})$. Then, $10 \mathrm{~mL}$ of acetone $(2 \mathrm{~mL} / \mathrm{min} \times 5 \mathrm{~min})$ was supplied from the reverse direction to each cartridge. The extracted solutions were collected in glass tubes, and then concentrated to $1 \mathrm{~mL}$ by repeating nitrogen gas purging and inner wall washing. Final solutions for the instrumental analysis of GC/MS or LC/MS/MS were reconstituted with hexane or acetone. Details of the SPE, nitrogen gas purge procedure and recovery ratio followed the conventional method (Kameya et al., 2010; Jinya et al., 2011; Kameya et al., 2012; Jinya, 2012; Kameya et al., 2014). In a previous laboratory experiment, more than $80 \%$ of chemicals examined had a recovery ratio of $50-140 \%$. Therefore, detected concentrations were used as the value whereby the concentration measured was rebated by the concentration ratio.

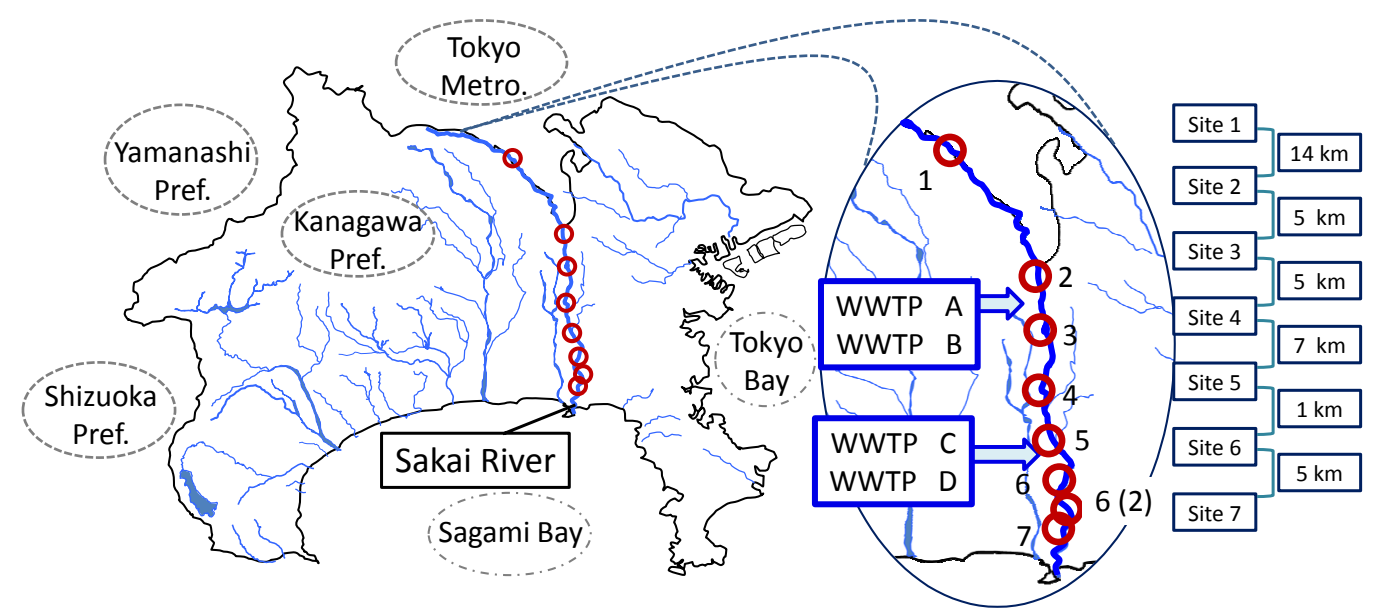

Fig. 1 - Locations of river water monitoring sites. 


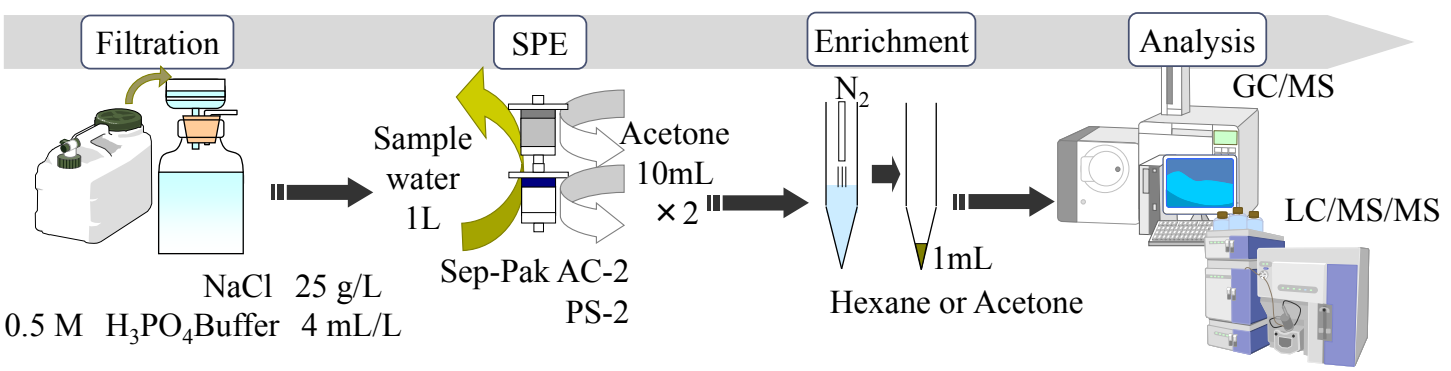

Fig. 2 - Procedure of pretreatment for water samples used in this study.

\section{Instrumental analyses}

In this study, 359 Japanese PRTR chemicals (388 including isomers) were analyzed, and $203(=562-359)$ others were excluded from the monitoring targets because the chemicals, such as metal compounds and volatile organic compounds, could not be analyzed under the same experimental conditions. Also, some chemicals could not be purchased commercially. Using the GC/MS system (QP2010 plus, Shimadzu, Kyoto, Japan), 287 chemicals (301 including isomers) were analyzed and using the LC/MS/MS system (TSQ Quantum Access MAX, Thermo Fisher Scientific, Kanagawa, Japan) 72 chemicals (87 including isomers) were analyzed.

The analysis by GC/MS was performed under the following conditions. The internal standard was added into the solution that had already been concentrated by the SPE method, and then $1 \mu \mathrm{L}$ of the solution was injected with splitless mode at $250^{\circ} \mathrm{C}$. The chromatography column, J\&W DB-5 ms $(30 \mathrm{~m} \times 0.25 \mathrm{~mm} \times 0.25 \mu \mathrm{m}$, Agilent Technologies, Tokyo, Japan), was used and the column temperature program was set to: (1) $40^{\circ} \mathrm{C}$ for the first $2 \mathrm{~min}$, (2) $310^{\circ} \mathrm{C}$ at $8^{\circ} \mathrm{C} / \mathrm{min}$, (3) and $310^{\circ} \mathrm{C}$ for $5 \mathrm{~min}$. Mass spectral analysis was conducted with the electron ionization (EI) mode and the total ion chromatogram (TIC) mode of a scan range from 33 to 600 amu and scan rate of 0.3 $\mathrm{sec} / \mathrm{scan}$. The analytical data was processed for identification and quantification using Compound Composer Software (Shimadzu, Kyoto, Japan) in which the retention time database, the mass spectrum database and the calibration curve database were already recorded (Kadokami et al., 2005).

The analysis by LC/MS/MS was also performed under the following conditions. Methanol was added into the acetone solution that had already been concentrated by the SPE method, and then $5 \mu \mathrm{L}$ of the solution was injected into the liquid chromatography column, Hypersil GOLD $(50 \mathrm{~mm} \times 2.1 \mathrm{~mm} \times 1.9 \mu \mathrm{m}$, Thermo Fisher Scientific, Kanagawa, Japan). The matrix effect by river water contaminants was also investigated by adding the standards together with methanol into the sample solution. The mobile phase consisted of methanol (A) and $2 \mathrm{mM}$ ammonium formate (B). The gradient conditions were as follows: The column was equilibrated with $1 \%$ mobile phase (A) for $0.5 \mathrm{~min}$, and then increased to $40 \%$ until $4 \mathrm{~min}, 90 \%$ until $12.1 \mathrm{~min}, 99 \%$ until $18.5 \mathrm{~min}$, and then returned to $1 \%$ until $19 \mathrm{~min}$ and equilibrated for $1 \mathrm{~min}$. The flow rate was kept constant at $200 \mu \mathrm{L} / \mathrm{min}$. Tandem mass spectral analysis was conducted with the electrospray ionization (ESI) mode and the multiple reaction monitoring (MRM) mode for positive or negative ion mode; spray voltage of 3,000 V for positive ion mode or $2,500 \mathrm{~V}$ for negative ion mode, tube lens voltage of $78 \mathrm{~V}$, ion transfer capillary 
temperature of $270^{\circ} \mathrm{C}$, vaporizer temperature of $450^{\circ} \mathrm{C}$, sheath gas $\left(\mathrm{N}_{2}\right)$ pressure of 50 psi, and auxiliary gas $\left(\mathrm{N}_{2}\right)$ pressure of 15 units. The analytical data was processed for identification and quantification using Xcalibur ${ }^{\mathrm{TM}}$ software (Thermo Fisher Scientific, Japan).

\section{RESULTS AND DISCUSSION}

\section{Numbers of chemicals detected / non-detected and their uses}

From the results of the monitoring for 359 PRTR chemicals for three years, 232 chemicals were detected. The numbers of chemicals detected/non-detected in the monitoring are shown in Fig. 3. Under the Japanese PRTR act, a PRTR report for Class I chemicals must be submitted because of their hazard and production volume, but no PRTR report for Class II chemicals is required because of their low production volume. A total of 184 Class I chemicals, which were reported in the PRTR data somewhere in Japan (METI, 2013), were detected. And only three Class I chemicals, which were not reported in the PRTR data, were detected. One hundred and twenty-three Class I chemicals in the target chemicals were not detected in this study. In contrast, 45 Class II chemicals were detected in this study, and 33 Class II chemicals were not detected. It was confirmed that even chemicals used in small amounts could be observed in river water as well as Class I chemicals.

The uses of the monitoring targets and the detected chemicals were classified as percentages of the number of chemicals and are shown in Fig. 4. There were three main groups for each use: (1) household (antimicrobial, surfactant, pharmaceutical), (2) pesticides (insecticide, herbicide, fungicide), and (3) industrial uses (all others). Industrial chemicals were the major type. The percentage of industrial use was higher in detected chemicals than that in monitoring targets. In contrast, the percentage of pesticides was lower in detected chemicals than that in monitoring targets. It was considered that there was less farmland in the surrounding area.

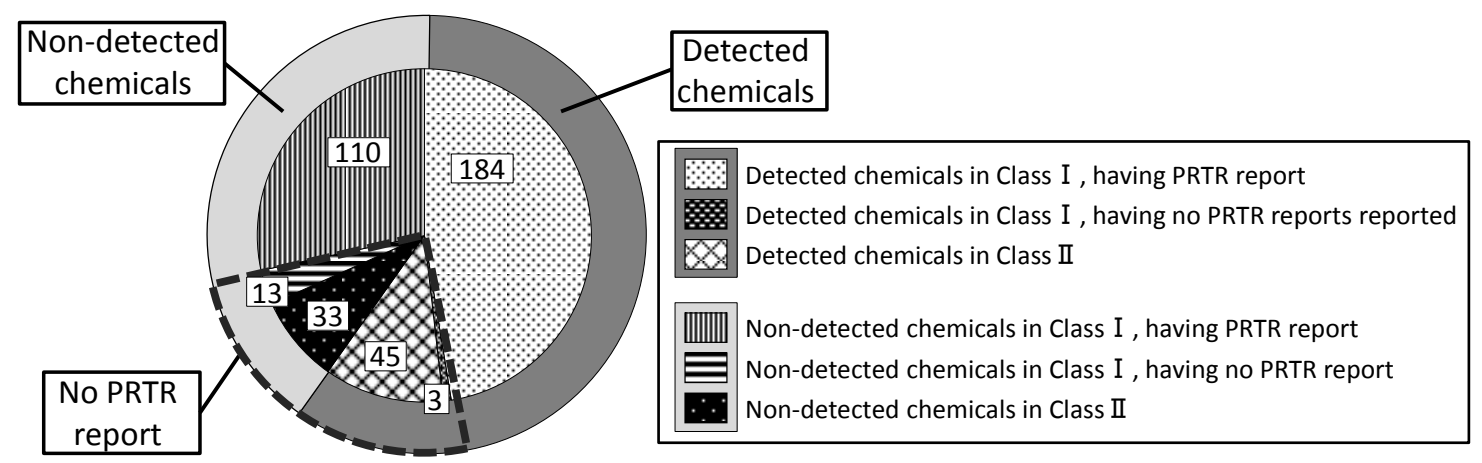

Fig. 3 - Numbers of PRTR chemicals detected / non-detected in monitoring. (compared to PRTR report in FY2011) 


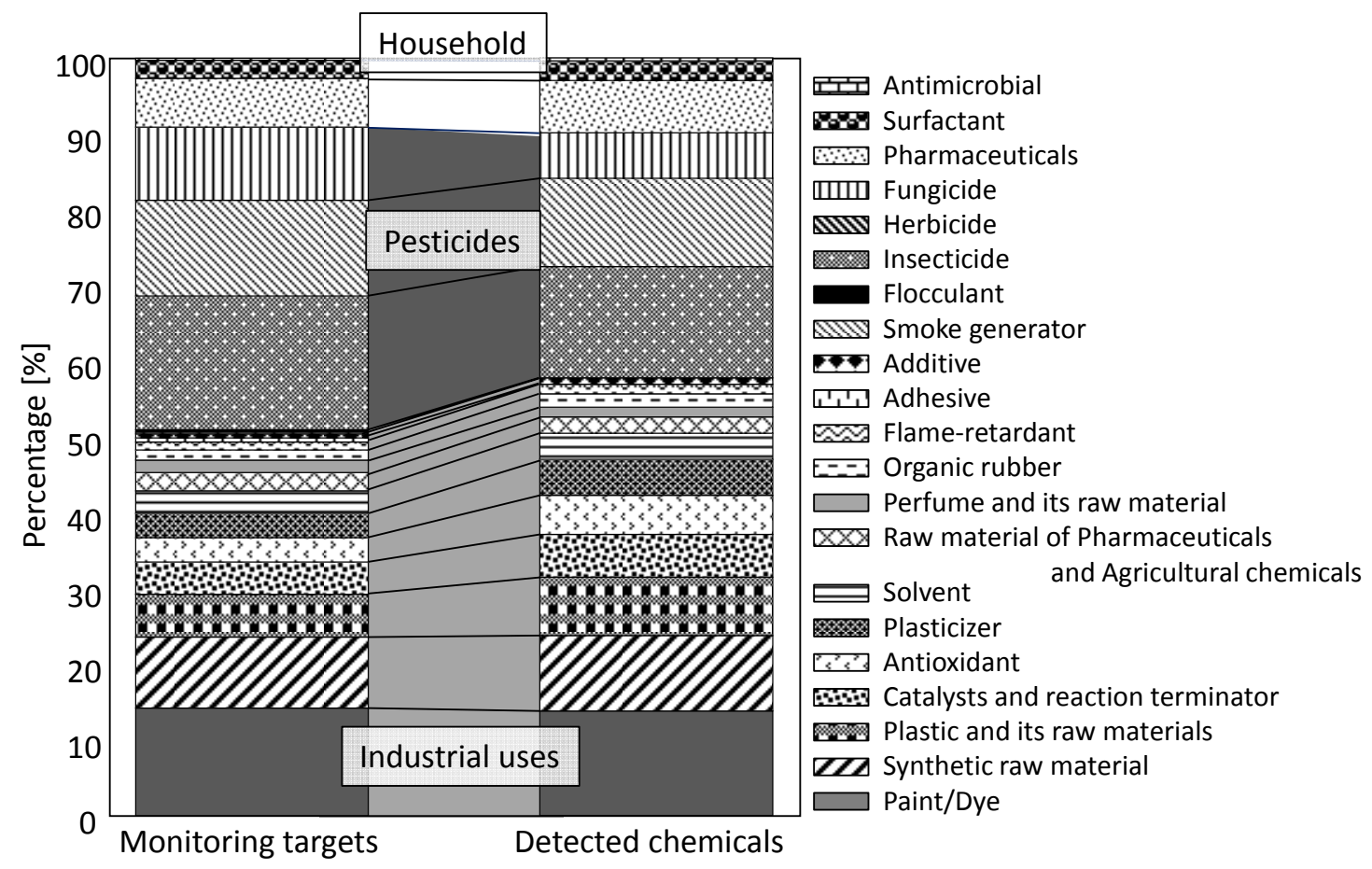

Fig. 4 - Usage of monitoring targets and detected chemicals.

\section{Chemicals detected at monitoring sites and PRTR data reported from nearby areas}

In previous reports, there were chemicals for which the removal in STPs was insufficient and they were discharged and detected in the river (Niina et al., 2005; Kathryn et al., 2012). At first, according to the PRTR data of FY 2011, seven facilities released 34 PRTR chemicals into Sakai River. Here, four of seven facilities were STPs. Only six chemicals in 34 types were target chemicals in this study: acrylamide (PRTR registration No. 1-2), EPN (1-48), simazine (1-113), thiobencarb (1-147), tetrachloroethylene (1-262) and trichloroethylene (1-281). Among them, five types, EPN (1-48), simazine (1-113), thiobencarb (1-147), tetrachloroethylene (1-262) and trichloroethylene (1-281), were discharged from the STPs. The results of the monitoring show that only three chemicals, simazine (1-113), thiobencarb (1-147) and tetrachloroethylene (1-262), were detected. Their concentrations were very low compared with the environmental water quality standards that were regulated for them. In contrast, some chemicals that have no PRTR reports were detected in high concentrations or at a high detection ratio as shown in the next section.

\section{Detection frequency of PRTR chemicals}

The detection ratio and median concentration for each chemical detected were calculated, and the distribution of the detection ratio for all the 388 (including isomers) monitoring target chemicals is shown in Fig. 5 (in ascending order of the detection ratio). Figure 5 is classified into three areas: area for non-detected chemicals, area for chemicals having a detection ratio of less than $50 \%$, and area for chemicals having a detection ratio of more than 50\%. Only $27(7 \%)$ chemicals had a detection ratio greater than $50 \%$, and a large portion of their uses was industrial use. In contrast, the detection ratios of pesticides were mostly less than $50 \%$. 


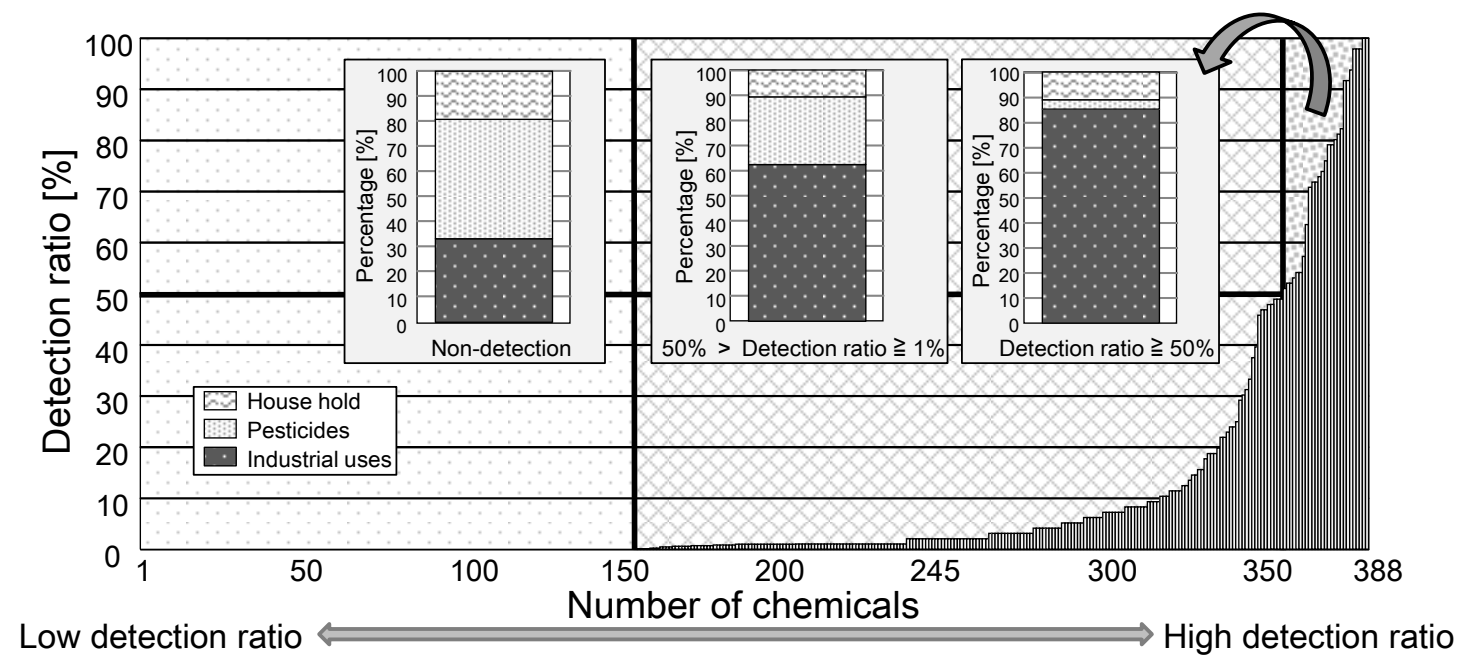

Fig. 5 - Distribution of the detection ratios in the total monitoring targets.

In the above 27 chemicals, there were 10 chemicals of which the median concentrations detected were greater than $0.1 \mu \mathrm{g} / \mathrm{L}$, while most of the chemicals detected were with low concentrations of less than $0.1 \mu \mathrm{g} / \mathrm{L}$. The European Union (EU) has set a maximum admissible concentration of $0.1 \mu \mathrm{g} / \mathrm{L}$ for individual pesticides and their related compounds in drinking water (EU, 1998) and the European Committee (EC) has set a ground water quality standard of $0.1 \mu \mathrm{g} / \mathrm{L}$ for pesticides (EC, 2006). Although there are differences in their hazards, the value of $0.1 \mu \mathrm{g} / \mathrm{L}$ might be a reference of contaminant. The detailed monitoring results of the chemicals, for which detection ratios higher than $50 \%$ and concentrations of more than $0.1 \mu \mathrm{g} / \mathrm{L}$ were observed, are shown in Table 2 . Here, the values of travel blank were $0.02 \mu \mathrm{g} / \mathrm{L}$ for diethyl phthalate $(1-353), 0.17 \mu \mathrm{g} / \mathrm{L}$ for di-n-butyl phthalate (1-354), $1.47 \mu \mathrm{g} / \mathrm{L}$ for bis(2-ethylhexyl)phthalate (1-355), 0.00 $\mu \mathrm{g} / \mathrm{L}$ (n.d.) for phthalandione (1-413), and $1.81 \mu \mathrm{g} / \mathrm{L}$ for dicyclohexyl phthalate (2-78). The contamination through the pretreatment process in the laboratory may not be negligible. Therefore, it was confirmed that the quantification for five phthalates was reliable.

The relationship between the detection ratio and the median concentration is classified and shown in Table 3 . There were 17 chemicals that had detection ratios of higher than $50 \%$ but low concentrations of less than $0.1 \mu \mathrm{g} / \mathrm{L}$, and 41 chemicals that had low detection ratios of less than $50 \%$ but high concentrations of more than $0.1 \mu \mathrm{g} / \mathrm{L}$. The other $320(82 \%)$ chemicals had low detection ratios and low concentrations. These results confirmed that the pollution of the water quality by the PRTR chemicals in Sakai River was not so high. 
Table 2 - Results of the monitoring for high detection ratios and high concentrations.

\begin{tabular}{ccccccc}
\hline $\begin{array}{c}\text { PRTR } \\
\text { Registration } \\
\text { No. }\end{array}$ & Name & Use & $\begin{array}{c}\text { Detection } \\
\text { ratio }[\%]\end{array}$ & $\begin{array}{c}\text { Median } \\
{[\mu \mathrm{g} / \mathrm{L}]}\end{array}$ & $\begin{array}{c}95 \% \text { tile } \\
{[\mu \mathrm{g} / \mathrm{L}]}\end{array}$ & $\begin{array}{c}\text { Blank } \\
{[\mu \mathrm{g} / \mathrm{L}]}\end{array}$ \\
\hline $1-208$ & 2,4-Di-tert-butylphenol & Antioxidant & 98 & 0.14 & 0.85 & N.D \\
\hline $1-269$ & Isophytol & Medical product & 79 & 0.14 & 0.28 & N.D \\
\hline $1-320$ & Nonylphenol & Surfactant & 92 & 0.18 & 0.91 & N.D \\
\hline $1-353$ & Diethyl phthalate & Plasticizer & 98 & 0.24 & 4.01 & 0.02 \\
\hline $1-354$ & Di-n-butyl phthalate & Plasticizer & 100 & 0.34 & 0.95 & 0.17 \\
\hline $1-355$ & Bis(2-ethylhexyl)phthalate & Plasticizer & 100 & 3.81 & 14.87 & 1.47 \\
\hline $1-413$ & Phthalandione & Plasticizer & 57 & 0.18 & 0.89 & N.D \\
\hline $1-440$ & Cumene hydroperoxide & Catalyzer & 82 & 0.11 & 0.37 & N.D \\
\hline $1-459$ & Tris(2-chloroethyl) phosphate & Flame retarder & 92 & 0.18 & 0.63 & N.D \\
\hline $2-78$ & Dicyclohexyl phthalate & Plasticizer & 79 & 0.30 & 2.53 & 1.81 \\
\hline
\end{tabular}

Table 3 - Relationship of detection ratio and concentration.

\begin{tabular}{|c|c|c|c|}
\hline & \multicolumn{3}{|c|}{ Detection ratio } \\
\hline \multirow{3}{*}{ 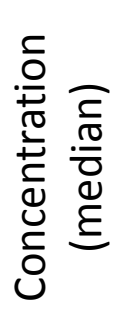 } & & low & high \\
\hline & 으 & 320 & 17 \\
\hline & 告 & 41 & 10 \\
\hline
\end{tabular}

1) Detection ratio more than / less than $50 \%$.

2) Concentration more than / less than $0.1 \mu \mathrm{g} / \mathrm{L}$.

\section{PRTR chemicals detected in each season and at each monitoring site}

The numbers of chemicals detected were counted by each monitoring site and each season, and summarized in Table 4. The numbers of chemicals detected at each site in each season ranged from 48 to 81 (from $12-21 \%$ ). Among these, only 27 to 33 chemicals were detected at all sites. Similarly, only 28 to 35 chemicals were detected in all seasons. Approximately half the chemicals that might be detected at each site or in a season were detected at all sites or in all seasons. In other words, approximately half the chemicals might not be detected by the monitoring at each site in a season. For this reason, multiple monitoring at multiple points might be required in order to evaluate the presence of PRTR chemicals in a certain river.

A list of chemicals that were detected at all the monitoring sites is shown in Table 5 using their PRTR registration No., and a list of chemicals that were detected in all seasons is shown in Table 6. The chemicals listed in the tables were easy to detect everywhere or in every season. The detections of the other chemicals, including pesticides, had a unique tendency at a specific site and/or a specific season. For example, chemicals such as triclopyr (1-286), butyl benzyl phthalate (1-356), 2-naphthol (1-393), 1,3-propane sultone (2-79) and 2-methyl-5-nitroaniline (2-92) were detected at only one site, and chemicals such as aniline (1-18), bisphenol A (1-37), 1,3-xylene (1-80), 
1,3,5-trimethylbenzene (1-297), 3-toluidine (1-299), 2-nitrotoluene (1-315) and methyl 4-hydroxybenzoate (1-334) were detected in only one season. In general, a pesticide is detected in one of two seasons, but the number of detected pesticides did not change in every season. Specific release sources might exist for those chemicals.

Table 4 - Number of chemicals detected at each site in each season.

\begin{tabular}{ccccccccc}
\hline season site & Site 1 & Site 2 & Site 3 & Site 4 & Site 5 & Site 6 & Site 7 & All sites \\
\hline Spring & 48 & 62 & 50 & 55 & 57 & 73 & 62 & 33 \\
\hline Summer & 60 & 49 & 49 & 55 & 49 & 67 & 57 & 29 \\
\hline Autumn & 53 & 55 & 50 & 62 & 49 & 48 & 51 & 27 \\
\hline Winter & 60 & 60 & 77 & 59 & 81 & 69 & 78 & 29 \\
\hline All seasons & 28 & 30 & 31 & 34 & 29 & 35 & 33 & 13 \\
\hline
\end{tabular}

Table 5 - List of chemicals detected at all monitoring sites.

\begin{tabular}{|c|c|c|}
\hline Season & \multicolumn{2}{|c|}{ PRTR registration No. of chemicals detected* } \\
\hline Spring & 33 kinds & $\begin{array}{l}1-18,1-53,1-73,1-74,1-76,1-86,1-181,1-208,1-240,1-269,1-273,1-296,1-299 \\
1-320,1-330,1-334,1-344,1-349,1-353,1-354,1-355,1-359,1-365,1-368 \\
1-370,1-383,1-413,1-416,1-440,1-459,1-462,2-49,2-78\end{array}$ \\
\hline Summer & 29 kinds & $\begin{array}{l}1-53,1-74,1-76,1-86,1-181,1-207,1-208,1-240,1-269,1-296,1-297,1-320 \\
1-330,1-344,1-349,1-353,1-354,1-355,1-359,1-365,1-368,1-383,1-391 \\
1-413,1-440,1-459,1-462,2-49,2-78\end{array}$ \\
\hline Autumn & 27 kinds & $\begin{array}{l}1-53,1-86,1-133,1-181,1-188,1-207,1-208,1-224,1-269,1-273,1-296,1-320 \\
1-330,1-353,1-354,1-355,1-359,1-365,1-368,1-383,1-391,1-413,1-416 \\
1-440,1-459,1-462,2-78\end{array}$ \\
\hline Winter & 29 kinds & $\begin{array}{l}1-37,1-53,1-73,1-74,1-80,1-133,1-207,1-208,1-224,1-240,1-269,1-273 \\
1-296,1-315,1-320,1-330,1-344,1-349,1-353,1-354,1-355,1-370,1-391 \\
1-413,1-416,1-440,1-459,1-462,2-78\end{array}$ \\
\hline
\end{tabular}

*Please check CHRIP (NITE, 2008) for names and properties of chemicals.

Table 6 - List of chemicals detected in all seasons.

\begin{tabular}{|c|l|l|}
\hline Site & \multicolumn{2}{|l|}{ PRTR registration No. of chemicals detected* } \\
\hline Site 1 & 28 kinds & $\begin{array}{l}1-53,1-74,1-188,1-207,1-208,1-240,1-269,1-273,1-296,1-320,1-330,1-344, \\
1-349,1-353,1-354,1-355,1-359,1-365,1-368,1-370,1-391,1-413,1-416, \\
1-440,1-459,1-462,2-78,2-92\end{array}$ \\
\hline Site 2 & 30 kinds & $\begin{array}{l}1-53,1-74,1-188,1-207,1-208,1-240,1-269,1-273,1-296,1-320,1-330,1-344, \\
1-349,1-353,1-354,1-355,1-359,1-365,1-368,1-370,1-391,1-413,1-416, \\
1-440,1-459,1-462,2-78,2-92\end{array}$ \\
\hline Site 3 & 31 kinds & $\begin{array}{l}1-18,1-53,1-74,1-76,1-86,1-181,1-188,1-207,1-208,1-240,1-269,1-273, \\
1-296,1-320,1-330,1-344,1-349,1-353,1-354,1-355,1-359,1-365,1-368, \\
1-383,1-391,1-413,1-440,1-459,1-462,2-49,2-78\end{array}$ \\
\hline Site 4 & 34 kinds & $\begin{array}{l}1-16,1-53,1-73,1-74,1-86,1-133,1-181,1-207,1-208,1-224,1-269,1-273, \\
1-296,1-319,1-320,1-330,1-334,1-344,1-349,1-353,1-354,1-355,1-365, \\
1-368,1-370,1-383,1-391,1-413,1-416,1-440,1-459,1-462,2-49,2-78\end{array}$ \\
\hline Site 5 & 29 kinds & $\begin{array}{l}1-53,1-74,1-86,1-133,1-188,1-207,1-208,1-240,1-269,1-273,1-296,1-297, \\
1-320,1-330,1-353,1-354,1-355,1-356,1-365,1-368,1-370,1-383,1-391, \\
1-413,1-440,1-459,1-462,2-49,2-78\end{array}$ \\
\hline Site 6 & 35 kinds & $\begin{array}{l}1-53,1-73,1-74,1-76,1-86,1-133,1-153,1-181,1-188,1-207,1-208,1-269, \\
1-273,1-296,1-320,1-330,1-349,1-353,1-354,1-355,1-365,1-368,1-370, \\
1-383,1-391,1-393,1-413,1-416,1-428,1-440,1-459,1-462,2-49,2-78,2-79\end{array}$ \\
\hline Site 7 & 33 kinds & $\begin{array}{l}1-18,1-53,1-74,1-76,1-86,1-133,1-181,1-207,1-208,1-240,1-265,1-269, \\
1-273,1-296,1-297,1-320,1-330,1-344,1-353,1-354,1-355,1-359,1-365, \\
1-368,1-383,1-413,1-416,1-428,1-440,1-459,1-462,2-49,2-78\end{array}$ \\
\hline
\end{tabular}

*Please check CHRIP (NITE, 2008) for names and properties of chemicals. 


\section{CONCLUSIONS}

In this study, 359 PRTR chemicals (388 including isomers) were monitored for three years, and 232 chemicals were detected in total. This is the first large-scale monitoring of PRTR chemicals in Japan. Most of the chemicals detected had a very low concentration, and low detection ratio. Only 10 of the industrial chemicals were found at high detection ratios and high concentrations. Some chemicals were detected only at a specific site or in a specific season. Therefore, the usefulness and need for environmental monitoring of PRTR chemicals were confirmed in this study. Multiple monitoring at multiple points might be required in order to evaluate the presence of PRTR chemicals in a certain river.

\section{ACKNOWLEDGEMENTS}

This research was supported by Environment-Responsive Technology Development Etc. (FY 2012) of the Ministry of Economy, Trade and Industry (METI) Japan and by the JSPS KAKENHI Grant-in-Aid for Scientific Research (B) (20310018).

\section{REFERENCES}

EC (European Commission) (2006) Directive 2006/118/EC of the European Parliament and the Council of December 12, 2006 on the protection of ground water against pollution and deterioration. European Commission, Brussels, Belgium.

EU (European Union) (1998) Council Directive 98/83/EC of November 3, 1998 on the quality of water intended for human consumption. European Union, Brussels, Belgium.

Jinya D. (2012) Development of solid-phase extraction method for simultaneous analysis of semi-volatile organic compounds using a GC-MS database system. SHIMADZU Technical Report, C146-0296, 8p. (http://www.an.shimadzu.co.jp/gcms/support/lib/pdf/c146-0296.pdf, accessed May 19, 2014) (in Japanese)

Jinya D., Iwamura T., Kadokami K. and Kusuda T. (2011) Development of a comprehensive analytical method for semi-volatile organic compounds in water samples by a combination of solid-phase extraction and gas chromatography-mass spectrometry database system, J. Environ. Chem., 21(1), 35-48.

Kadokami K., Tanada K., Taneda K. and Nakagawa K. (2005) Novel gas chromatography-mass spectrometry database for automatic identification and quantification of micropollutants. J. Chromatogr. A, 1089(1-2), 219-226.

Kameya T., Konuma K., Kondo T., Matsumoto Y., Katsumata H., Kobayashi T. and Fujie K. (2014) Nitrogen purge condition for simultaneous GC/MS measurement of chemicals. J. Water Environ. Technol., 12(2), 161-175.

Kameya T., Saito M., Kondo T., Toriumi W., Fujie K., Matsushita T. and Takanashi H. (2012) Detection of fenitrothion and its degradate 3-methyl-4-nitrophenol in water environment. J. Water Environ. Technol., 10(4), 427-436.

Kameya T., Yamazaki K., Kobayashi T. and Fujie K. (2010) Ecological assessment of water quality by three-species acute toxicity test and GC/MS analysis - A case study of agricultural drains -. J. Water Environ. Technol., 8(3), 223-230.

Kathryn N. K., Rebecca R. P., Allison D. D., Shannon M. P., John J. K., Christopher G. P. and Kimberly A. G. (2012) Effects of anthropogenic inputs on the organic quality 
of urbanized streams. Water Res., 46(8), 2515-2524.

METI (Ministry of Economy, Trade and Industry) (2013) Release of FY 2011 PRTR Data, Summary of Statistical Results Regarding Released and Transferred Amounts of Chemical Substances. Ministry of Economy, Trade and Industry, Government of Japan. (http://www.meti.go.jp/english/press/2013/0228_03.html, accessed May 19, 2014)

MOE (Ministry of Environment) (2003) PRTR Information Hiroba (PRTR information plaza Japan). Ministry of the Environment, Government of Japan. (http://www.env.go.jp/en/chemi/prtr/prtr.html, accessed May 19, 2014)

Niina L., Tuula T. and Leif K. (2005) Occurrence of acidic pharmaceuticals in raw and treated sewages and in receiving waters. Water Res., 39(11), 2219-2228.

NITE (National Institute of Technology and Evaluation) (2008) Chemical Risk Information Platform. National Institute of Technology and Evaluation, Japan. (http://www.safe.nite.go.jp/english/db.html, accessed May 19, 2014)

UNEP (United Nations Environment Programme) (2006) Strategic Approach to International Chemicals Management (SAICM). United Nations Environment Programme, Nairobi, Kenya. (http://www.saicm.org/, accessed May 19, 2014) 